\title{
A TEORIA DO VALOR-TRABALHO E O PREÇO DOS MEDICAMENTOS
}

\author{
THE LABOUR THEORY OF VALUE AND THE PRICE OF MEDICINES
}

\author{
Mariana Lannes Lindenmeyer ${ }^{1}$ \\ Eder Dion de Paula Costa ${ }^{2}$ \\ Wesley Pereira Tomaz ${ }^{3}$
}

\section{RESUMO}

Este artigo pretende analisar a questão do valor, buscando conhecer os parâmetros que substanciam a sua expressão. A partir do método dedutivo e da revisão bibliográfica, pretende-se resgatar a contribuição marxista sobre o tema, caracterizando, com isso, o valor enquanto forma social histórica e típica do capitalismo. A análise perpassa a produção e a circulação de mercadorias, demonstrando, nessas esferas, a existência de condições objetivas que formam o valor. Durante a exposição, os pressupostos da teoria do valor são contrapostos por argumentos da escola neoclássica de economia, responsável pela produção da teoria subjetiva do valor. $\mathrm{Na}$ segunda parte do artigo, buscou-se explicar os preços dos medicamentos a partir da teoria marxista do valor-trabalho, demonstrando, com isso, a sua pertinência enquanto teoria apta a explicar os fenômenos sociais.

Palavras-chave: Teoria do valor. Produção de mercadorias. Medicamentos.

\section{ABSTRACT}

This paper aims to analyze the question of value, searching for the parameters that substantialize its expression. Through the use of the deductive method and the bibliographic review, it is intended to rescue the Marxist elaborations on this subject, thus, characterizing the value as a historical social form pertinent to capitalism. The analysis runs through the production and circulation of commodities, demonstrating, in those fields, the existence of objective conditions that constitute value. During the exposition, the assumptions of labour theory of value are compared to those of the neoclassic school of economy, accountable for the production of the subjective theory of value. In the second part of the paper, we sought to explain the prices of medicines with the Marxist labour theory of value, showing, with that, its pertinence regarding the explanation of social phenomena.

Keywords: Theory of value. Production of commodities. Medicines.

\footnotetext{
${ }^{1}$ Graduada em Direito pela Universidade Federal do Rio Grande - FURG. Especialista em Direito do Estado pela Universidade Federal do Rio Grande do SUL - UFRGS e em Direito Processual Civil pela Escola Superior da Magistratura Federal do Rio Grande do SUL - ESMAFE. Mestranda em Direito e Justiça Social pela Universidade Federal do Rio Grande - FURG.

${ }^{2}$ Graduado em Direito pela Universidade Federal do Rio Grande - FURG. Mestre em Direito pela Pontífica Universidade Católica do Rio Grande do Sul - PUCRS. Doutor em Direito pela Universidade Federal do Paraná.

${ }^{3}$ Graduado em Direito pela Universidade Federal do Rio Grande - FURG. Mestrando em Direito e Justiça Social pela Universidade Federal do Rio Grande - FURG.
} 


\section{INTRODUÇÃO}

Pretende-se, com este trabalho, analisar um dos aspectos mais fundamentais do modo de produção capitalista: o valor. Assim, utiliza-se teoria de base marxista para a conceituação do problema, que é a delimitação dos pressupostos que compõem o valor. $\mathrm{O}$ valor, como definido por Rubin (1982, p. 27) é uma forma social típica do capitalismo, cujo processo é tanto um processo de produção das condições materiais de existência da vida humana, quanto um processo que se desenvolve através de relações específicas, histórico-econômicas, de produção e, portanto, o processo que produz e reproduz os expoentes deste processo, suas condições materiais de existência e suas mútuas relações, isto é, sua forma econômica determinada de sociedade. Por isto, as relações entre pessoas e o movimento das coisas dentro do processo de produção estão indissoluvelmente unidos no processo de troca, de sorte que as trocas só são realizadas como resultado da ação conjunta destes dois aspectos.

O estudo tem início pela forma mercadoria, célula do sistema capitalista a partir da qual se expressa socialmente o valor. Entendendo as relações de produção pode-se delimitar o caráter objetivo do valor, amparado no trabalho humano necessário à produção das mercadorias. A partir disto, a discussão passa a ter o contraponto da teoria que sugere a subjetividade humana como a responsável por atribuir socialmente o valor.

Após a exposição das postulações que embasam a teoria marxista do valor, na segunda parte do trabalho, abordar-se-á a questão do preço dos medicamentos, a fim de demonstrar a aptidão desta teoria em explicar este fenômeno. Em razão da natureza da produção destas mercadorias, aponta-se, ainda, a dificuldade da parte mais pobre da classe trabalhadora em adquirir os medicamentos, o que, indubitavelmente, é uma tendência gerada pelas próprias dinâmicas internas do modo capitalista.

Na segunda parte do trabalho, abordar-se-á a questão do preço dos medicamentos, a fim de demonstrar a adequação da teoria do valor para explicar este fenômeno e também como as dinâmicas do capital influenciam o destino da classe trabalhadora no que se refere ao consumo destas mercadorias.

\section{A TEORIA DO VALOR-TRABALHO}

Existe larga produção teórica a respeito do valor e este artigo se propõe a ser um resgate da teoria marxista do valor-trabalho, diante de um certo predomínio recente da teoria subjetiva 
do valor, tão celebrada pelos economistas neoclássicos. Para que se possa entender o valor, fazse necessário, antes, um breve estudo sobre a mercadoria.

Se abstrairmos todas as especificidades das mercadorias, veremos que todas possuem um valor,detentor de um caráter duplo, o fato de ser um valor de uso e o de ser um valor de troca. $\mathrm{O}$ valor de uso corresponde à relação qualitativa da mercadoria, isto é, a sua utilidade, a sua capacidade de satisfazer necessidades humanas, que podem ser do corpo ou do espírito ${ }^{4}$. O responsável por atribuir o valor de uso é o trabalho humano que, a partir das suas especificidades, transforma a natureza e atribui caráter útil às mercadorias. Por sua vez, o valor de troca refere-se à relação quantitativa, a proporçãona qual valores de uso de um tipo são trocados por valores de uso de outro tipo.

Para que se possa explicar como é possível quantificar o valor dos distintos valores de uso é necessária nova abstração. Se desconsiderássemos o valor de uso de uma mercadoria, estaríamos também renunciando a todos os seus componentes e formas físicas que fazem dela um valor de uso, de tal forma que o produto não é mais uma mesa ou qualquer coisa útil, tampouco é fruto de qualquer trabalho produtivo determinado. Desaparecendo o caráter útil do trabalho nas mercadorias expressados, perecem também todas as diferentes formas específicas destes trabalhos, que não mais se distinguem uns dos outros, sendo todos reduzidos ao dispêndio de atividade cerebral, tecidos musculares, etc., uma "geleia de trabalho" (MARX, 2011, p. 161), o trabalho humano abstrato.

Este trabalho humano abstrato é mais do que o mero trabalho fisiologicamente igual, é a forma social específica sob a qual se dá a igualação dos trabalhos na sociedade capitalista, a partir da comparação, no mercado, dos frutos dos diferentes tipos de trabalho. Tem-se, portanto, queembora a criação de valor se dê na esfera produtiva, é somente a partir da circulação de mercadorias que o valor pode se expressar socialmente, de tal sorte que, caso um produto não ultrapasse a barreira do uso pessoal não será mercadoria e o trabalho nele contido será improdutivo - já que não houve produção de valor, uma vez que a troca não se efetuou no mercado.

Assim, a grandeza de valor é comensurada a partir da quantidade de trabalho contido em uma mercadoria, o tempo, medido em horas, socialmente necessário à produção desta mercadoria. Este considera o trabalho humano igual, o mesmo dispêndio da mesma força de

\footnotetext{
${ }^{4}$ Este é um trecho geralmente mal compreendido na exposição de Marx (2011, p. 157) em O Capital. Comumente esta passagem é utilizada para atestar a suposta produção de mercadorias imateriais, mas a leitura atenta do trecho não permite esta interpretação; o que Marx de fato escreveu é que as mercadorias podem satisfazer necessidades oriundas da imaginação, e não que as mercadorias possam ser fruto da imaginação.
} 
trabalho humano ${ }^{5}$. Desta forma, é o tempo necessário de trabalho para produzir valor de uso sob as condições normais de produção de uma dada sociedade, com a intensidade a habilidade usual, e somente este tempo é o que determina a grandeza de seu valor (MARX, 2011, p. 163). Por esta razão, a teoria do valor não se propõe a explicar preço individual de produto, ou analisar a produção individual, mas, busca entender o valor na totalidade capitalista.

Como, na sociedade capitalista, as relações sociais são reificadas, a relação entre os diferentes produtores privados de mercadorias se dá por intermédio do mercado. Em verdade, por conta dareificação, a relação passa a ser dar entre coisas e, por esta razão, não há qualquer relação subjetiva entre elas, de modo que os anseios e aspirações dos seus produtores e a vontade dos consumidores se tornam irrelevantes no mercado. O que medeia esta relação entre as mercadorias são condições materiais, objetivas, portanto. O observa Rubin (1982, p. 22) que, devido à estrutura da sociedade mercantil, devido à ausência de regulação social direta da atividade de trabalho dos membros da sociedade, os vínculos entre empresas individuais, autônomas, privadas, são realizados e mantidos através das mercadorias, coisas, produtos do trabalho. Neste sentido, a troca aparece como um elenco indispensável no processo de reprodução, pois, à mesma medida que assegura a independência de uma pessoa em relação as outras, cria, também, um sistema de dependência mútua em relação as coisas.

E é assim que se explica como valores de uso de diferentes tipos se equiparam no mercado. É pela quantidade de trabalho contido nas mercadorias. A partir da abstração do caráter útil de todos os trabalhos, tem-se a categoria de trabalho abstrato, ou seja, o dispêndio de capacidades humanas para um fim qualquer e, assim, é possível quantificar o trabalho contido nas mercadorias.

Uma crítica comum à teoria do valor é de que Marx, supostamente, teria postulado a existência do valor absoluto, pois o trabalho realizado pelo indivíduo seria incorporado na mercadoria e esta passaria a valer-se em função daquele. Evidentemente, isto é falso. O valor só se expressa a partir da troca, quando os produtos dos diferentes trabalhos são comparados em um mercado. Esta natureza implica, por si, que o valor não é absoluto, mas sim relativo; Marx, aliás, era duro crítico de Ricardo, este sim defensor de um valor absoluto.

Outra crítica recorrente à Marx é que ele, supostamente, teria deixado de considerar a subjetividade humana em sua teoria. Ocorre que Marx nem por um instante deixou de considerar

\footnotetext{
${ }^{5}$ Desta forma, se assumíssemos que o tempo socialmente necessário à produção de uma cadeira é de duas horas, caso um trabalhador produzisse a mesma cadeira em quatro horas, não observaríamos acréscimo no valor desta mercadoria; isto indicaria apenas que o trabalhador indispõe da tecnologia necessária à produção em tempo razoável, ou que é preguiçoso ou inábil.
} 
a subjetividade humana, afinal esta tem influência no mercado; qualquer compra que não for estritamente necessária à sobrevivência do indivíduo satisfará, claro, a sua subjetividade; o valor de uso é o suporte material do valor, afinal.

Entretanto, a subjetividade diz respeito à aquisição ou não das mercadorias, nada diz sobre o valor destas mesmas mercadorias. A subjetividade não interfere no valor: o que Marx questionou e que a economia neoclássica não explica é como a subjetividade humana pode ser a substância do valor, como o desejo humano pode ser mensurado economicamente? Como é possível equalizar, matematicamente, a vontade humana? A resposta mais satisfatória a partir desta pergunta é a de que, a partir do comportamento médio, é possível estipular certas tendências de comportamento, e a partir destas a formulação matemática é possível. Entretanto, esta resposta refuta, justamente, a teoria do valor subjetivo, já que, ao reconhecer que, na média, humanos comportam-se economicamente de uma certa forma, está se afirmando que há padrões objetivos que permeiam esta subjetividade e que, portanto, o valor não pode ser subjetivo. Se o valor fosse subjetivo, as relações de valor teriam uma aleatoriedade tal que impossibilitaria a abordagem científica. $\mathrm{O}$ que a teoria marxista do valor-trabalho se propõe a investigar, portanto, é quais são as relações materiais objetivas que compõem o valor.

Outro ponto é que os custos de produção, para quem produz, são um fato objetivo, não subjetivo. Mesmo que se utilizasse a teoria subjetiva, em que a oferta se daria mediante um dado preço a partir do qual o produtor deseje produzir, permanece inarredável o fato de que a produção só pode existir, idealmente, enquanto os custos de produção forem inferiores ao valor total produzido; esta é uma condição objetiva da qual capitalista algum pode escapar.

A expressão do valor, na verdade, independe da vontade humana, já que é alicerçado em bases materiais de produção; estas relações independem da vontade dos indivíduos para acontecer, por dizerem respeito às dinâmicas internas do sistema capitalista.

Acima de tudo, a realidade é a real refutadora da teoria do valor subjetivo. Utilizando dados fornecidos pelo Finanzen, o portal sobre mercado financeiro mais prestigiado na Alemanha, coletou-se dados - angariados a partir do balanço financeiro destas instituições sobre empresas dos mais distintos ramos. A Ferrari, popular fabricante de carros esportivos teve uma taxa de lucro média, de 2013 a 2019, 18,63\%. O conglomerado suíço de artigos de luxo, Richemont, teve uma taxa de lucro média, no mesmo período, de 18,68\%. Louis Vuitton, especializada na produção de bolsas e malas, no mesmo período, teve uma taxa de lucro média de $19,49 \%$. Diferentes empresas, de diferentes ramos, entretanto a taxa de lucro permaneceu estável. Pergunta-se: seria possível que os números fossem assim tão próximos por obra da 
subjetividade humana? Seria o acaso o responsável por criar uma harmonia tão perfeita? É evidente que não, é cristalino que há parâmetros objetivos que substanciam o valor.

As empresas capitalistas, através da competição, tendem a convergir para uma taxa de lucro média. Se, por exemplo, surgisse uma nova mercadoria, cujo valor é de 100 reais, mas que, por conta da subjetividade humana, pelo fato de o produto ser uma grande novidade, este seja vendido por 400 reais, o que ocorreria na sequência é que surgiria uma nova empresa no ramo que venderia o mesmo produto com uma taxa de lucro menor, e assim por diante, até que se chegue numa taxa de lucro média no setor.

\title{
3 O PREÇO DOS MEDICAMENTOS
}

Estes são os pressupostos base da teoria marxista do valor-trabalho. Até aqui pouco foi utilizada a expressão "preço", pois o seu emprego requer, primeiro, uma desmistificação. Uma crítica frequente à teoria marxista do valor é a de que esta não explica os preços de mercado e que, por essa razão, seria falha. Trata-se, evidentemente, de mais um argumento falacioso, pois não só a teoria do valor explica os preços como é a única capaz de fazê-lo.

\begin{abstract}
O economista vulgar não faz a mínima ideia de que as relações de troca reais, do dia-adia, e as grandezas do valor não podem ser imediatamente idênticas. A piada da sociedade burguesa está precisamente em que a priori não existe qualquer regulação social consciente da produção. $\mathrm{O}$ racional e naturalmente necessário impõe-se apenas como média atuando cegamente. E então o economista vulgar crê fazer uma grande descoberta quando, no que respeita à revelação da conexão interna, proclama que as coisas na aparência parecem diferentes. De facto, está a proclamar que se agarra à aparência e que a toma como a última palavra. Para quê então, em suma, uma ciência? (MARX, 1982, p. 456)
\end{abstract}

Aqui Marx aponta para o fato de que o preço e o valor não coincidem, justamente porque o preço é a aparência, uma distorção do valor. De que serviria a ciência se a aparência e a essência coincidissem imediatamente?

\footnotetext{
$\mathrm{Na}$ verdade, todo desvio de produção, seja para mais ou para menos, desencadeia forças que põem um fim ao desvio na direção dada, e dão origem a movimentos na direção oposta. A expansão excessiva da produção leva a uma queda de preços no mercado. Isto leva a uma redução da produção, abaixo mesmo do nível necessário. A redução posterior da produção faz cessar a queda de preços. A vida econômica é um mar de movimentos flutuantes. Não é possível, em momento algum, observar o estado de equilíbrio na distribuição de trabalho entre os vários ramos de produção. Mas, sem esse estado de equilíbrio, concebido teoricamente, o caráter e a direção do movimento de flutuação não podem ser explicados. (RUBIN, 1982, p. 93)
} 
Rubin, assim, escancara a infertilidade de analisar preços isolados, reforçando a ideia marxista de totalidade. $\mathrm{O}$ argumento central da escola neoclássica é de que o preço de mercado resulta de um ponto de equilíbrio gerado a partir das curvas da oferta e da demanda, em que a oferta corresponde àquilo que os produtores desejam ofertar a cada preço possível, de tal sorte que em caso de excesso de oferta, o preço das mercadorias deverá cair. A demanda, de seu turno, representa aquilo que os demandantes desejam demandar a cada preço possível. Neste sentido, o excesso de demanda corresponde a uma elevação do preço, e o excesso de oferta a uma queda.

A seguir, um gráfico, similar àqueles estampados em manuais de economia de ampla divulgação no ensino da economia no Brasil.

Gráfico 1 - Preço e quantidade de equilíbrio

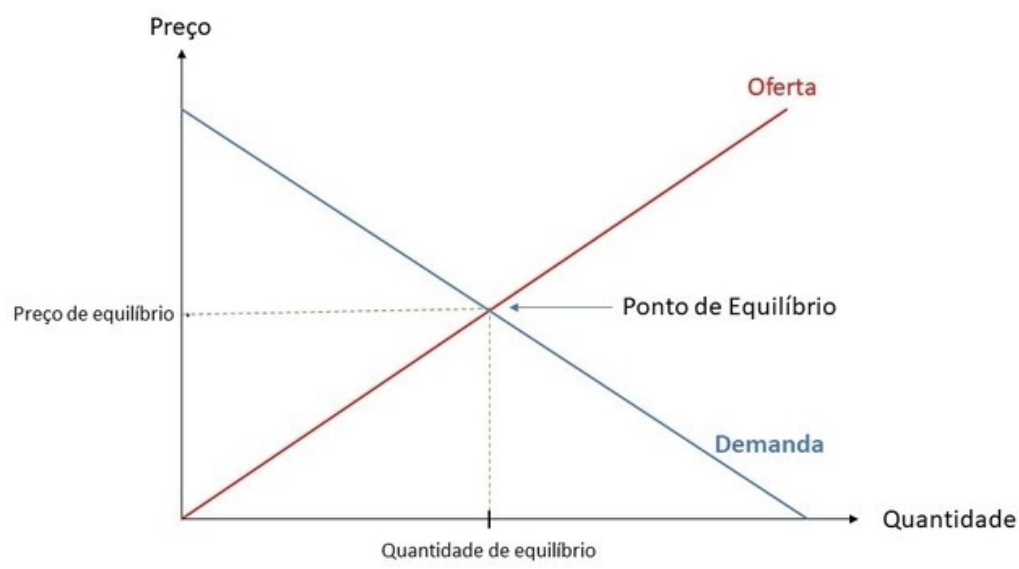

Fonte: Site Dicionário Financeiro ${ }^{6}$.

No gráfico acima, vemos uma linha crescente de oferta e uma linha decrescente de demanda e que o preço de equilíbrio acontece em um dado momento destas trajetórias. A pergunta mais pertinente que pode ser feita neste cenário é: por que o preço de equilíbrio foi atingido naquele dado ponto? Por que não poderia ter sido atingido anteriormente, ou posteriormente; por que naquele exato ponto?

Esta "teoria" nos brinda com um recorte estático da realidade, e por isso é incapaz de captar o movimento real do objeto. Para os adeptos desta vertente econômica, o preço de mercado representa um equilíbrio entre oferta e demanda, de modo que as trocas são realizadas a partir desse pressuposto. Entretanto, por meio do teorema de Sonnenschein-Mantel-Debreu ${ }^{7}$, foi

\footnotetext{
${ }^{6}$ Disponível em: <https://www.dicionariofinanceiro.com/oferta-e-demanda/>. Acesso em: 16 out. 2020.

${ }^{7}$ Refere-se a uma série de trabalhos científicos cujo resultado é que a função excesso de demanda não é restringida pelas usuais restrições de racionalidade sobre demandas individuais na economia, de modo que premissas de racionalidade microeconômicas não tem implicações macroeconômica correspondentes. Foram assim publicados
} 
demonstrado matematicamente que este ponto de equilíbrio pode não ser garantido, ou, ainda que o seja, podem existir múltiplos pontos de equilíbrio para as mesmas curvas de demanda e oferta. Já rui, desde logo, o argumento central da formulação neoclássica sobre a formação dos preços; entretanto, ainda que assumíssemos verdadeira a postulação de que o preço corresponde ao equilíbrio entre as curvas de oferta e demanda, daí resulta uma tautologia; trata-se de um argumento circular.

Em uma sala de aula de um curso de economia, em algum momento da exposição, o professor pronunciaria a seguinte frase: "em um dado mercado, oferta e demanda fixam um preço". Alguém mais atento pode porventura questionar, "mas por que foi este o preço fixado e não qualquer outro?", e, como resposta teria, "porque este foi o preço fixado pela oferta e pela demanda". Uma lógica circular que a nada responde.

Para entender por que o tal preço de equilíbrio se deu em cinco e não em dez reais, somente a teoria marxista do valor-trabalho pode socorrer-nos. É pela quantidade de trabalho socialmente necessária à sua produção que uma dada mercadoria possui o preço de equilíbrio fixado em uma dada grandeza e não em outra. Dessa forma, pode-se dizer que o valor é a base material sobre a qual flutuam os preços. Com isto não se está negando que a demanda e a oferta exerçam influência sobre o preço; evidentemente influenciam-no, mas não o determinam. Entretanto, o que garante que a grandeza de valor sobre a qual o preço irá flutuar será de dez ou cinco reais é a quantidade de trabalho socialmente necessário, e não o equilíbrio entre oferta e demanda, e menos ainda a subjetividade humana.

Esclarecido o conceito de preço, resta agora analisar a questão dos medicamentos. De início, cumpre-nos mencionar, em termos economicistas, que a demanda da saúde é inelástica, ou seja, o aumento do preço das mercadorias resulta numa queda do consumo proporcionalmente inferior a este aumento, em razão da essencialidade do consumo de mercadorias desta natureza. Trocando em miúdos, significa dizer que o preço destas mercadorias terá pouca influência sobre a sua demanda.

Pode-se, então, proceder à análise dos preços dos medicamentos. Para tanto, alguns apontamentos sobre a competição capitalista são necessários, isto porque, ainda que cada

internacionalmente: Sonnenschein, H. (1972). Market excesso-demandfunctions. Econometrica. 40 (3): 549-563; Sonnenschein, H. (1973). Do walras' identity and continuity characterize the class of community excess-demand functions? Journal of Economic Theory. 6: 345-354. Mantel, R. (1974). On the characterization of aggregate excess-demand. Journal of Economic Theory. 7: 348-353; Debreu, G. Excess-demand functions. Journal of Mathematical Economics.1. 15-21. 
capitalista escolha o preço de acordo com suas curvas de custos, funções de demanda e etc., os preços de mercado são conjuntamente determinados, por intermédio da competição entre os diversos capitalistas daquele setor.

Embora exista, dentro do campo da economia, um extenso debate sobre a concorrência e o seu papel na economia capitalista, poderíamos entende-la como a busca constante por vantagens competitivas, sendo estas mais eficazes quando estiverem amparadas sobre uma inovação, pois, do ponto de vista da produção, uma inovação sempre culminará com a queda do tempo social necessário à produção de uma dada mercadoria, o que significa duas coisas: a mercadoria terá um valor menor e será pago um valor menor pela força de trabalho. Embora no imaginário popular a ideia que se tenha sobre um capitalista é que este deseja vender suas mercadorias pelo maior valor possível, trata-se justamente do contrário, ele deseja que a mercadoria possua a menor quantidade possível de valor, para que seja mais barato produzi-la e, sendo um valor menor, ser acessível ao consumo de um número maior de pessoas. Com as constantes inovações nos meios de produção, é garantido que o trabalhador se aproprie cada vez menos do valor total produzido. Mesmo que por qualquer motivo haja um aumento salarial, o novo salário será ainda uma parte menor da riqueza total que é apropriada pelo trabalhador. Supondo que todas as demais variáveis permaneçam constantes, se em um ano de trabalho todas as trabalhadoras de uma dada empresa receberem um salário mensal de 3 mil reais, sobre a riqueza total de 100 mil reais e, no ano seguinte estas mesmas trabalhadoras receberem um salário de 3 mil e 500 reais, sobre a riqueza total de 500 mil reais, mesmo com acréscimo salarial, o seu percentual sobre a riqueza total produzida é menor do que no ano anterior. Com isto, logicamente não se está argumentando que o aumento salarial não deva ser reivindicação das trabalhadoras, é, na verdade, o oposto; estas deveriam se apropriar de toda a riqueza que produziram.

Sobre a produção de mercadorias, em uma indústria de inovação, para a criação dos assim chamados medicamentos referência, será desenvolvida uma nova molécula, cujo desenvolvimento exige anos de trabalho. Geralmente, inicia-se com estudos computacionais que simulam a ligação molecular que o medicamento irá efetuar no organismo, e, após isto, são escolhidas as moléculas que serão sintetizadas e avaliadas, para serem submetidas a testes e, se aceitas pelo órgão regulador do país, finalmente permitindo a produção do medicamento.

O acesso à tecnologia de síntese, que não é usualmente disponível para a comercialização e precisa ser desenvolvida pelo interessado, podendo os prazos de desenvolvimento variar de poucos meses a mais de um ano, a depender da complexidade do produto e da experiência da empresa envolvida no processo; e a curva de aprendizado, pois, como em vários setores econômicos, os custos de produção de 
fármacos se reduzem à medida que aumenta a produção total acumulada, razão pela qual um produtor novo, mesmo dispondo do conhecimento da rota de síntese de um fármaco, obtido em escala laboratorial, terá grandes dificuldades iniciais para produzir a custos equivalentes aos dos produtores já estabelecidos, a não ser que consiga desenvolver uma inovação no processo (PALMEIRA; PAN, 2003, p. 9).

Nota-se, desde já, a alta complexidade que envolve a produção de medicamentos. Por esta razão, o valor dos medicamentos referência tende a ser alto, pela alta complexidade e quantidade de trabalho humano necessário à sua produção. Soma-se a isto um necessário trabalho de divulgação - marketing -, necessário para criar o instinto de consumo do fármaco em questão, de modo que o valor deste trabalho de divulgação terá de compor $^{8} \mathrm{o}$ da mercadoria.

De seu turno, os medicamentos genéricos, por serem produzidos a partir de uma tecnologia de síntese já existente, têm reduzido drasticamente o valor socialmente necessário à sua produção, e isto justifica o seu preço mais baixo. Mas, como para a existência do genérico é necessária, antes, a produção do medicamento referência, tem-se que, invariavelmente, é necessário muito trabalho social para a produção destas mercadorias. A questão sobre o preço dos medicamentos será sempre tensa enquanto houver a forma mercadoria e, por esta razão, uma parte significante da classe trabalhadora sempre terá um acesso dificultado a mercadorias desta natureza.

De qualquer forma, o fator principal para o alto preço dos medicamentos ainda não é este. Segundo dados disponíveis no anuário estatístico do Instituto Latino Americano de Estudos Socioeconômicos ${ }^{9}$, de 2012 a 2018 a taxa de lucro média do setor foi de 30,31\%, o que é uma taxa de lucro elevada, se comparada aos demais setores de produção.

Aliando-se a uma já exuberante taxa de lucro, há as assim chamadas "falhas de mercado". $\mathrm{O}$ mercado dos medicamentos possui algumas particularidades que o diferenciam dos demais tipos de mercados existentes. A primeira destas reside na assimetria de informação, ou seja, o fato de que o consumidor, por si só, é incapaz de atestar a qualidade do medicamento, é necessário o parecer técnico de alguém socialmente credenciado para tal. Por sua vez, este prescritor terá menos informação do que o laboratório produtor da mercadoria. Dessa forma, a competição capitalista é abalada, já que o acesso à informação não é livre; os economistas costumam chamar estas desigualdades competitivas de "falha de mercado".

\footnotetext{
${ }^{8} \mathrm{O}$ que aumenta é o custo da produção, não o tempo socialmente necessário à produção da mercadoria. No caso do medicamento, o trabalho de marketing não é necessário para produzir o medicamento, mas sim para inseri-lo no mercado.

${ }_{9}^{9}$ Disponível em: http://ilaese.org.br/anuario-estatistico-ilaese-trabalho-e-exploracao-2019-2/ Acesso em: 16 out. 2020.
} 
Se considerarmos, ainda, que os indivíduos que prestam o cuidado e os produtores de medicamentos podem atuar de maneira cartelizada, e dessa forma, a discriminação do preço em muito se afastaria do valor real do produto, tem-se aqui outra "falha de mercado".

Logicamente, a formação de monopólios ou oligopólios - tendência do sistema capitalista - é uma outra "falha de mercado". Outro fator que não poderia deixar de ser mencionado é a existência de patentes, direitos de propriedade intelectual protegidos internacionalmente por intermédio de acordos, que visam à garantia de um monopólio absoluto temporário aos detentores dos produtos ou processos patenteados. Como isto se constitui em abalo à competição, temos aqui mais uma "falha de mercado".

As marcas mais estabelecidas no mercado, ainda que não mais detenham patente sobre seus produtos, ainda assim se constituem em monopólio relativo, pois, ainda que outras empresas tentem competir ofertando produtos por um preço menor, a fidelidade às marcas garantirá que os produtos sigam sendo prescritos e adquiridos, o que lhes confere uma vantagem competitiva considerável sobre os demais concorrentes. Temos aqui outra "falha de mercado".

É curioso notar que as tais "falhas de mercado" sempre beneficiam os capitalistas maiores. O que os economistas chamam de falha de mercado é apenas efeito da acumulação capitalista, que tende a ser cada vez mais concentrada. As patentes, por exemplo, são apenas uma forma específica de assegurar juridicamente a prevalência dos burgueses maiores sobre os menores. Portanto, trata-se apenas de um aparato jurídico cuja função é a de legitimar socialmente, por intermédio do Estado, a formação de um monopólio; as tais falhas de mercado são, assim, apenas as formas particularespelas quais os capitalistas forram seus bolsos.

E é por isto que há, geralmente, um divórcio tão violento entre o valor e o preço dos medicamentos, e por isto a sua aquisição é tão penosa para a classe trabalhadora. E é também por esta razão que não importa o quanto teorizem os economistas burgueses, jamais conseguirão corrigir as tais "falhas de mercado", porque elas são apenas a manifestação da acumulação de capital. O mercado, mesmo sendo uma criação humana, foge do seu controle; nada ou ninguém é capaz de controla-lo. A existência do mercado é uma falha incorrigível.

Tem-se, assim, por que a produção de medicamentos como mercadorias é problemática na sociedade capitalista, já que, por requerer um alto volume de trabalho social, estas mercadorias terão sempre um valor relativamente elevado.

Esta condição é especialmente nociva para países de economia dependente, como o Brasil, e a América Latina em geral, pois, diante das profundas desigualdades sociais aqui 
experimentadas, as farmácias e o uso excessivo de medicamentos constituem-se na fonte primária de prestação da saúde. Com o custo elevado dos medicamentos aliado ao alto desemprego existente no Brasil, a tendência é que estes medicamentos se tornem cada vez mais dificilmente acessados pela classe trabalhadora.

\section{CONCLUSÃO}

Pretendeu-se, com este trabalho, apresentar a teoria marxista do valor para além das imprecisões e inverdades usualmente veiculadas pelos cientistas burgueses. Para tanto, iniciou-se com o estudo da mercadoria, sua produção e circulação, pois, a partir disto, é possível conhecer os pressupostos objetivos que constituem o valor.

A partir da exposição dos pressupostos básicos da teoria, fez-se o contraste à teoria subjetiva do valor e buscou afastar as incompreensões mais comuns a respeito da proposição de Marx.

Ao fim, fez-se a análise do preço dos medicamentos, com o intuito de demonstrar a pertinência desta teoria para explicar os fenômenos sociais, mas, ainda mais, visando apontar o problema da produção de medicamentos e de que forma isto é prejudicial para a classe trabalhadora.

Longe de esgotar a problemática, este artigo é um convite à reflexão sobre o valor, um dos pontos centrais da sociedade capitalista. Assim, espera-se fomentar o debate acerca do valor e, sobretudo, a respeito do preço dos medicamentos no Brasil.

\section{REFERÊNCIAS}

FINANZEN.NET.Portal de finanças. Baden-WurttembergFinanzen, 2020. Disponível em: http://finanzen.net. Acesso em: 15 out. 2020.

ILAESE. Anuário estatístico sobre trabalho e exploração no Brasil. São Paulo: ILAESE, 2019. v. 1, n. 2. Disponível em: http://ilaese.org.br/anuario-estatistico-ilaese-trabalho-eexploracao-2019-2/. Acesso em: 15 out. 2020.

MARX, Karl. Cartas de Marx a Kugelmann. Tradução de José Barata-Moura e João Pedro Gomes. Lisboa: Editorial Avante, 1982. 
MARX, Karl. O Capital, Livro I. Tradução de Rubens Enderle. São Paulo: Boitempo, 2011.

RUBIN, Isaak. A teoria marxista do valor. Tradução de José Bonifácio S. Amaral Filho.São

Paulo: Polis, 1987. 